\title{
A presença negra na América Latina
}

Rafael Domingos Oliveira ${ }^{1}$

\section{Resenha}

ANDREWS, George Reid. América Afro-Latina. 1808-2000. Tradução: Magda Lopes. São Carlos: EDUFSCar, 2014.

A primeira vez que se teve notícia do uso do termo América Afro-Latina foi quando, em 1978, Anani Dzidzienyo publicou o artigo “Activity and Inactivity in the Politics of Afro-Latin America”, nos anais do periódico Secolas². Em 1980, o professor haitiano de estudos latino-americanos Pierre-Michel Fontaine publica "The Political Economy of Afro-Latin America"3. Estes dois artigos marcam, de modo heurístico, o início de um campo de estudos que se estenderia, com certa timidez, até os dias atuais. Este novo livro de George Reid Andrews, publicado em 2007 e traduzido no Brasil em 2014, representa uma síntese do debate iniciado há 40 anos, e um grande ganho para a historiografia sobre tema.

Andrews é um historiador estadunidense, professor na Universidade de Pittsburgh e já bem conhecido entre historiadores brasileiros. É de sua autoria o livro Negros e brancos em São Paulo4, publicado no Brasil em 1998 (o original é de 1991), no qual analisa as consequências, para a população negra do Estado de São Paulo, das políticas de branqueamento empreendida pela imigração de europeus. Parte considerável da obra se dedica a compreender a competição travada entre negros e brancos no mercado de trabalho, como resultado da não inserção daqueles no mundo do trabalho livre, e de sua luta pela mobilidade social e pela influência política. Já o seu The Afro-Argentines of Buenos Aires, 180o19005 (não traduzido), analisa o mito de "desaparecimento" da população negra

\footnotetext{
${ }^{1}$ Estudante de pós-graduação (mestrado) em História pela Universidade Federal de São Paulo. Contato: rafael.historiasocial@gmail.com

2 DZIDZIENYO, Anani. "Activity and Inactivity in the Politcs of Afro-Latin America". Secolas Annals, 9, pp. 48-61, 1978.

3 FONTAINE, Pierre-Michel. "The Political Economy of Afro-Latin America". Latin American Research Review. V. 15, n. 2, pp. 111-141, 1980.

4 ANDREWS, George Reid. Negros e brancos em São Paulo (1888-1988). Tradução de Magda Lopes. Bauru: EDUSC, 1998 [original de 1991].

5 Idem. The Afro-Argentines of Buenos Aires, 1800-1900. Madison: University of Wisconsin Press, 1980.
} 
argentina na primeira metade do século XIX. Sua conclusão é a de que, diferente do que está arraigado em estudos anteriores, a população negra argentina diminuiu a partir da ostensiva imigratória como política de branqueamento do Estado, ocorrida ao final do oitocentos. Essa diminuição, entretanto, não representou o desaparecimento das populações com ascendência africana, revelando apenas a diluição dos marcadores raciais na sociedade.

Estes seus dois importantes estudos já anunciavam algumas das questões centrais levantadas em América Afro-Latina, que de algum modo sistematiza e amplia o escopo da discussão levada a cabo. Como aponta, a presença de africanos na América, e o seu papel para a estruturação das futuras nações do Novo Mundo, foi melhor estudada pela historiografia no que diz respeito às três regiões do continente compreendidas por Estados Unidos, Brasil e Cuba, sobretudo numa perspectiva comparada. As demais localidades constituintes da chamada América Latina - territórios ocupados e dominados desde o século XVI até o século XIX por Espanha e Portugal, com quem travaram lutas pela independência -, a despeito de terem recebido grandes quantidades de africanos na condição de escravizados, raramente motivaram estudos sobre o tema. Países como Argentina, Colômbia, Peru, México e Uruguai, nos mais variados graus, foram palco de intensos conflitos de natureza racial, estruturaram suas instituições pautados em desigualdades sociais e, de um modo geral, alimentaram e assumiram como oficial o discurso da democracia racial, a partir das experiências de mestiçagem.

Desse modo, a população negra dessas regiões vivenciou experiências compartilhadas, elaborando o quadro geral das diásporas africanas nas Américas. Com efeito, o estudo de Andrews constitui uma importante possibilidade de compreensão da história de africanos e seus descendentes na América Latina, das suas formas de resistência frente ao sistema escravista, das organizações e associações que que criaram, e do modo como reelaboraram as políticas de Estado então decretadas. As balizas temporais de América Afro-Latina iniciamse em 1800, período de desagregação dos diversos sistemas coloniais que organizavam a estrutura política da região, e findam nos anos 2000, nos quais ainda estão presentes as duras permanências do sistema de trabalho compulsório a que as populações negras estiveram submetidas. 
O capítulo 1, analisa as táticas e estratégias utilizadas pelas populações escravizadas, que muito se assemelham em diversas regiões do hemisfério sul do continente. Essas ações, entendidas como formas de resistência, são, para o autor, o grande legado da escravidão para as populações afrodescendentes, contrariando uma leitura, como a de Florestan Fernandes, que alegou a falta de autodisciplina e da vida familiar e laços comunitários como resultado da escravidão ${ }^{6}$. Para Andrews, ao contrário disso, já no século XIX os escravizados haviam criado redes de comunidades de fugitivos, como os quilombos que, em alguns casos, possuíam uma quantidade de pessoas superior à população em cativeiro, dependendo da região. $\mathrm{O}$ aspecto associativo da população escravizada, segundo o autor, foi uma marca que atravessou o tempo, e se fez notar nas diversas irmandades e organizações políticas criadas por mulheres e homens negros.

Associações e organizações que são os temas centrais dos capítulos 2 e 3 . Em "As guerras pela liberdade, 1810-1890", o autor evidencia a participação de escravizados e libertos nas frentes dos exércitos de libertação nacional, como uma forma de atuação política que tinha como foco a emancipação do julgo colonial. Além disso, é neste momento que o debate abolicionista ganha proeminência, e onde também essa população irá atuar mais efetivamente. Uma clivagem é percebida pelo autor: ao mesmo tempo que a escravidão era abolida nas regiões continentais, o Brasil e o Caribe espanhol aumentavam seu fluxo de africanos transportados em navios negreiros. Essa diferença marcou de forma decisiva a atuação desses sujeitos nas sociedades em questão, o que se expressou nas diferentes instituições culturais derivadas das tradições africanas.

Já em "A política da liberdade, 1810-1890", Andrews evidencia as saídas tomadas pelas diferentes nações latino-americanas após o fim da escravidão. No caso de países como Argentina, Brasil, Cuba e Uruguai, ocorreu um grande incentivo para que fossem bem-sucedidas as políticas imigratórias, que trouxeram o incremento europeu às sociedades. Como resultado, a negação do passado escravista converteu-se numa europeização das sociedades, que se expressou por meio do "branqueamento" dos povos, tido como um objetivo ora explícito, ora implícito. De modo diferente, Panamá, Costa Rica, República

\footnotetext{
${ }^{6}$ Cf. FERNANDES, Florestan. A integração do negro na sociedade de classes. 3. ed. São Paulo:
} Ática, 1978, v. 1. 
Dominicana e outros países, receberam imigrantes das Índias Ocidentais, que ao invés de ocasionar o "branqueamento" das populações, acabou por enegrece-las.

Esses dois fenômenos, acrescidos pelo boom de exportação ocorrido nesses anos, tiveram um profundo impacto nas sociedades locais e nos seus cidadãos de ascendência africana. O tema é desenvolvido no capítulo 4 , "O Branqueamento, 1880-1930", no qual o autor analisa documentos relativos aos diversos movimentos de trabalhadores surgidos na virada do século. Nestas associações, prevalecia o caráter multirracial, principalmente na forma pela qual as pessoas e os grupos reconheciam-se entre si, e a si próprios. As imagens acerca do outro e as formas de autorrepresentação social, influíram no modo como esses grupos elaboraram suas estratégias de luta por melhores condições de trabalho, ao mesmo tempo que eram resultados de amplos processos de miscigenação que muitas vezes acabavam por negar o passado africano e escravista do qual descendiam boa parte destes sujeitos.

No capítulo 5, "Amorenamento e o Enegrecimento, 1930-2000", Andrews explica como esses movimentos e organizações acabaram por constituir a base social, e também eleitoral, sob as quais os regimes populistas, que entre 1930 e 1940 assumiram o poder na maior parte da América Latina, assentaram seus discursos. Nesse período, as populações negras vivenciaram turbulentas contradições: as políticas de branqueamento deslocaram-se para visões de “democracia racial”, fazendo com que práticas sociais e culturais de origens africanas, como o samba, o candombe e a capoeira - antes perseguidos tornassem-se símbolos nacionais. Nessa toada, com a crescente urbanização e industrialização, que tiveram ritmos diferentes em diferentes regiões do continente, abriu-se possibilidades de ascensão e mobilidade sociais antes não conhecidas pela população negra. Por outro lado, o racismo, expresso nos preconceitos e discriminações difusas nas sociedades, continuava a ser uma barreira que impedia o avanço das pautas raciais. As ditaduras militares, as políticas reacionárias e o acirramento da luta de classes, motivaram uma nova onda de mobilização política, de caráter racial, protagonizada pela população negra no Brasil, na Colômbia e em outros países.

O sexto e último capítulo, "Entrando no século XXI, 2000 em diante", tem um perfil de inventário das lutas políticas travadas no campo social pelos afrodescendentes, e também de um levantamento das questões ainda prementes 
vividas por essa população. Passado mais de um século - em alguns casos dois da abolição do tráfico de africanos e do fim da escravidão, as populações de ascendência africana ainda enfrentam problemas ligados às condições materiais de existência, ao acesso aos direitos civis básicos e ao racismo que se revela tanto nas instituições quanto no cotidiano. Para Andrews, esse cenário é resultado das formas pelas quais as diferentes nações latino-americanas lidaram com a desagregação do sistema escravista, mas não só: as políticas de "branqueamento", a inclusão de negros como força de trabalho livre e as maneiras como os Estados encararam politicamente a ação de movimentos e grupos organizados, explicam o porquê a América Latina relegou às populações negras uma posição subalterna. Daí decorre recuperar o papel e a atuação dessas populações, que fazem do continente ao sul uma verdadeira América Afro-Latina.

A perspectiva comparativa adotada por Andrews possui como ônus sua rápida passagem por temas que poderiam ser explorados com mais substância. $\mathrm{O}$ mesmo acontece devido ao seu amplo recorte temporal. Mas de nenhum modo esses limites esvaziam a qualidade de sua análise, pautada num dilatado conhecimento sobre as realidades sociais e políticas da América Latina e do papel que as populações negras assumiram e assumem nessas sociedades. A diversidade da documentação da qual dispõe, o rigor conceitual e a sua fundamentação historiográfica, são exemplos que explicam a qualidade do trabalho ora apresentado e o seu lugar de destaque na produção sobre o tema.

George Reid Andrews traz à tona debates fundamentais para a compreensão das experiências compartilhadas pelas populações negras latinoamericanas, e sistematiza processos históricos que dão sentido às lutas ainda necessárias pelo reconhecimento da contribuição negra para essas sociedades, que ainda assistem - muitas vezes de modo dissimulado - ao racismo estrutural e dissolvido no cotidiano, anunciado pelos fossos das desigualdades sociais, do trabalho precarizado e do genocídio da juventude negra. Por tudo isso, é um trabalho que deve ser lido e de onde devem partir outros estudos de relevância historiográfica e social. 